\title{
Bivalirudin use in acute coronary syndrome patients undergoing percutaneous coronary interventions in Poland: Clinical update from expert group of the Association on Cardiovascular Interventions of the Polish Cardiac Society
}

Łukasz Kołtowski ${ }^{1}$, Jacek Legutko ${ }^{2}$, Krzysztof J. Filipiak ${ }^{1}$, Artur Dziewierz ${ }^{3}$, Stanisław Bartuś4, Paweł Buszman ${ }^{4,5}$, Piotr Buszman ${ }^{6,7}$, Dariusz Ciećwierz ${ }^{8}$, Maciej Dąbrowski ${ }^{9}$, Sławomir Dobrzycki ${ }^{10}$, Robert Gil ${ }^{11}$, Jarosław Gorący ${ }^{12}$, Marek Grygier ${ }^{13}$, Miłosz Jaguszewski ${ }^{8}$, Janusz Kochman ${ }^{1}$, Jacek Kubica ${ }^{14}$, Wiktor Kuliczkowki ${ }^{15}$, Piotr Lodziński ${ }^{1}$, Andrzej Ochała ${ }^{16}$, Krzysztof Reczuch ${ }^{17}$, Adam Witkowski ${ }^{9}$, Wojciech Wojakowski ${ }^{18}$, Jarosław Wójcik ${ }^{19}$, Dariusz Dudek ${ }^{20,21}$

${ }^{1} 1^{\text {st }}$ Department of Cardiology, Medical University of Warsaw, Poland

${ }^{2}$ Department of Interventional Cardiology, Jagiellonian University Medical College, John Paul II Hospital, Krakow, Poland

${ }^{3} 2^{\text {nd }}$ Department of Cardiology, Jagiellonian University Medical College, Krakow, Poland ${ }^{4}$ Department of Epidemiology and Statistics. Medical School of Silesia, Katowice, Poland

${ }^{5}$ Department of Cardiovascular Research, American Heart of Poland, Ustron, Poland ${ }^{6}$ Center for Cardiovascular Research and Development, American Heart of Poland, Katowice, Poland

${ }^{7}$ Andrzej Frycz Modrzewski Krakow University, Krakow, Poland

${ }^{8} 1^{\text {st }}$ Department of Cardiology, Medical University of Gdansk, Poland

${ }^{9}$ Department of Interventional Cardiology and Angiology, Institute of Cardiology, Warsaw, Poland

${ }^{10}$ Department of Invasive Cardiology, Medical University of Bialystok, Poland

${ }^{11}$ Department of Invasive Cardiology of the Center of Postgraduate Medical Education,

Central Hospital of the Internal Affairs Ministry and Administration, Warsaw, Poland

${ }^{12}$ Department of Cardiology, Pomeranian Medical University, Szczecin, Poland

${ }^{13}$ Department of Cardiology, Poznan University of Medical Sciences, Poznan, Poland

${ }^{14}$ Department of Cardiology and Internal Medicine, Collegium Medicum,

Nicolaus Copernicus University, Bydgoszcz, Poland

${ }^{15}$ Department and Clinic of Cardiology, Wroclaw Medical University, Wroclaw, Poland

${ }^{16}$ Invasive Cardiology and Electrocardiology Department,

Medical University of Silesia, Katowice Poland

${ }^{17}$ Department of Heart Diseases, Wroclaw Medical University, Wroclaw, Poland

${ }^{18}$ Department of Cardiology and Structural Heart Diseases,

Medical University of Silesia, Katowice, Poland

19“IKARDIA" Hospital of Invasive Cardiology, Naleczow, Poland

${ }^{20} 2^{\text {nd }}$ Department of Clinical Cardiology and Cardiovascular Interventions,

Jagiellonian University Hospital, Krakow, Poland

${ }^{21}$ Institute of Cardiology, Jagiellonian University Medical College, Krakow, Poland

Address for correspondence: Łukasz Koltowski, MD, PhD, $1^{\text {st }}$ Department of Cardiology, Medical University of Warsaw, ul. Banacha 1a, 02-097 Warszawa, Poland, e-mail: lukasz@koltowski.com 


\section{Introduction}

Coronary artery disease is one of the most common dysfunctions of the cardiovascular system [1]. Anticoagulant therapy is particularly important in the periprocedural period in the case of invasive treatment of acute coronary syndrome (ACS). Since the last consensus statement of the Polish expert group for Association on Cardiovascular Interventions of the Polish Cardiac Society published in 2014 [2], new circumstances have occurred that triggered the group to revise the viewpoint: 1) the new European Society of Cardiology guidelines on myocardial revascularization announced in 2018 provided indications for the use of bivalirudin in ACS; 2 ) new studies were published that provided essential new clinical evidence [3-6]; and 3) updated bivalirudin reimbursement code now allows for its unlimited use in myocardial infarction (MI) patients in Poland [7]. This is a 5-year update of the recommendations on the use of bivalirudin for percutaneous coronary intervention (PCI) of in ACS, tailored to the Polish healthcare setting.

\section{Thrombus formation in ACS and after PCI}

Percutaneous coronary intervention aims to restore the flow through the coronary artery in the setting of ACS. However, it is also associated with an increased risk of stent thrombosis. The incidence of thrombosis in contemporary drug-eluting stent is approximately $0.7 \%$ over 1 year [8]. The risk is higher in the case of stent implantation in the setting of ACS as compared to the elective angioplasty, which is affected by disturbed properties of the coagulation system and a reduced response to pharmacotherapy. Nevertheless, proper pharmacotherapy with antiplatelet and anticoagulant agents may reduce this risk.

\section{The mechanism of action of bivalirudin vs. unfractionated heparin}

Bivalirudin is a synthetic polypeptide consisting of 20 amino acids. Unlike unfractionated heparin (UFH), the mechanism of its action is independent of antithrombin, so is classified as direct thrombin inhibitors. This effect applies to the fluid phase and clot-bound of thrombin. Compared to UFH, which inhibits just about $50 \%$ of thrombin activity, bivalirudin suppresses it entirely allowing for effective and predictable anticoagulation effect. The inhibition of thrombin takes place in two mechanisms.
One of them is the inhibition of the active catalytic site of thrombin, and the second is the impact on the fibrin binding site (exosite 1). This means bivalirudin is able to inhibit active thrombin as well as thrombin bounded to platelets in a thrombus. In addition, platelet activation typical for UFH is not observed after bivalirudin, which reduces thrombin-dependent platelet aggregation by affecting the protease-activated receptor [9]. In contrary to UFH, bivalirudin, a direct thrombin inhibitor, is not dependent on the levels of antithrombin 3 . After intravenous administration, the onset of bivalirudin action is rapid, reaching a maximum serum concentration after 15-20 minutes. The half-life time of bivalirudin is approximately 25 minutes, which is more than two times shorter than an hour of UFH [10]. Bivalirudin is administered as an intravenous bolus of $0.75 \mathrm{mg} / \mathrm{kg}$. It is then followed by an infusion of $1.75 \mathrm{mg} / \mathrm{kg}$ throughout the time of the procedure that should be continued up to 4 hours after PCI. Such a pharmacological profile is particularly beneficial in case of periprocedural administration of anticoagulants. As in the case of UFH, the anticoagulant effect of bivalirudin can be assessed on-site by active clothing time and in laboratory by activated partial thromboplastin time [11]. In case of overt bleeding, the following methods are recommended to restore proper blood coagulation in bivalirudin recipients: ultrafiltration and hemodialysis, administration of recombinant factor VIIa, cryoprecipitate or fresh frozen plasma [12].

\section{Bivalirudin in the revascularization of the myocardium in ACS}

The 2018 European Society of Cardiology guidelines on the myocardial revascularization indicate that anticoagulation should be selected according to both ischemic and bleeding risks, and according to the efficacy-safety profile of the chosen agent. Although, routine use of UFH is indicated (class of recommendations I; level of evidence B), the routine use of bivalirudin as an alternative to UFH may be considered in patients with ST-segment elevation myocardial infarction (STEMI) (class of recommendations IIb; level of evidence A) and in selected patients with non-ST-segment elevation acute coronary syndrome (class of recommendations IIb; level of evidence A) [7].

Since the publication of the above guidelines, essential trials comparing the efficacy and safety of bivalirudin in comparison with UFH have been published. One-year results of the Minimizing Adverse Hemorrhagic Events by Transradial 
Access Site and Systemic Implementation of Angiox (MATRIX) randomized trial showed in a group of 7213 patients comparable rate of major adverse cardiac event (MACE)/net adverse clinical events between bivalirudin and UFH in the setting of STEMI and non-ST-segment myocardial infarction (NSTEMI). However, secondary endpoint analysis revealed in patient treated with bivalirudin comparted to UFH arm a significant decrease in all bleedings ( $13.6 \%$ vs. $15.9 \%, \mathrm{p}<0.05)$, major bleedings, i.e. Bleeding Academic Research Consortium (BARC) type 3 and 5 (2.2\% vs. 3.3\%, $\mathrm{p}<0.001)$, all-cause mortality (3.6\% vs. $4.6 \%$, $\mathrm{p}<0.05)$ and cardiovascular death $(2.2 \%$ vs. $3.0 \%$, $\mathrm{p}<0.05)$ [3]. On the other hand, there was a numerically higher rate of definite or probable stent thrombosis (1.4\% vs. $1.2 \%$ ) in bivalirudin group during the follow-up. Half of patients in MATRIX trial were pre-treated with $\mathrm{P}_{2} \mathrm{Y}_{12}$ inhibitors before catheterization procedure and ticagrelor or prasugrel were used in $1 / 3$ of patients [13]. Of note, a lack of prolonged bivalirudin infusion after PCI did not increase this risk of stent thrombosis, repeat revascularization or MACE. In contrary, the VALIDATE-SWEDEHEART randomized trial, which was taken into consideration in the myocardial revascularization guidelines, showed in a group of 6006 STEMI and NSTEMI patients a numerically lower rate of definite stent thrombosis in the bivalirudin group as compared to UFH $(0.4 \%$ vs. $0.7 \%$, $\mathrm{p}=0.09$ ) [14]. It should be underlined that nearly all patients $(97 \%)$ received potent $\mathrm{P}_{2} \mathrm{Y}_{12}$ inhibitors (ticagrelor or prasugrel). Although, the composite primary end-point consisting of all-cause mortality, MI or major bleeding, did not differ between the two arms, there was a trend of benefit in the bivalirudin treated female patients $(13.6 \%$ vs. $17.1 \%$, $\mathrm{p}=0.05)$ over a period of 180 days. The risk of major bleeding in both arms was the same (8.6\%).

The latest meta-analysis published in 2018 by Anantha-Narayanan that included 22 randomized studies and four subgroup analysis with 53,364 patients compared the use of the bivalirudin to heparin, with and without adjunctive glycoprotein IIb/IIIa inhibitors (GPI) in PCI [5]. Over a mean follow-up of $192 \pm 303$ days, the major bleeding was lower in the bivalirudin group with (risk ratio [RR] 0.64, 95\% confidence interval [CI] 0.53-0.77, $\mathrm{p}<0.001$ ) and without (RR $0.71,95 \%$ CI 0.51-0.99, $\mathrm{p}=0.041$ ) provisional or routine use of GPIs. There was no difference in all-cause mortality (RR 0.93 ; 95\% CI 0.82-1.05, $\mathrm{p}=0.260)$, target vessel revascularization (RR 1.17; 95\% CI 0.93-1.46, $\mathrm{p}=0.174$ ) or stroke (RR $0.91 ; 95 \%$ CI $0.71-1.18$, $\mathrm{p}=0.490$ ), despite a higher risk of stent thrombosis in bivalirudin group (RR 1.32; 95\% CI 1.04-1.68, $\mathrm{p}=0.022$ ).

In pre-treated patients, who received UFH before cathlab admission (ambulance/emergency department), the use of bivalirudin is feasible and had been correlated with lower risk of all-cause mortality and MACE comparted to the continuation of UFH [4].

\section{Bivalirudin as an anticoagulant therapy in high bleeding risk patients}

Bivalirudin is recommended and should be used as an alternative to UFH in patients with heparin-induced thrombocytopenia (class of recommendations I; level of evidence C) [7].

The use of non-vitamin $\mathrm{K}$ antagonist oral anticoagulants (NOACs) in primary and secondary prevention of stroke among Polish patients with atrial fibrillation presenting with ACS is rapidly increasing.

Considering the ORBITA trial results, we should also expect a growing number of patients with complex coronary artery disease and/or peripheral artery disease treated with low-dose rivaroxaban ( $2.5 \mathrm{mg}$ b.d.) on top of acetylsalicylic acid, coming to the cathlab for subsequent interventional procedures due to ACS [15]. Importantly, their use is associated with an increase of major bleeding events during urgent PCI. In the clinical practice, there is very limited possibility to assess the anticoagulation activity of dabigatran and xabans, especially in a timely manner required in the acute setting of ACS. Patients on NOACs were excluded from most of the trials, tough given the consistently low rates of bleeding with bivalirudin compared to heparin, it may be prudent to use bivalirudin in patients who have taken the last dose of NOAC within 4 hours. Measures to reduce this risk over the acute, periprocedural period include use of radial access, refrain from GPI and use of bivalirudin instead of UFH [16]. Furthermore, high bleeding risk has been identified in patients $>75$ years of age, female, obese (body mass index $[\mathrm{BMI}]>30 \mathrm{~kg} / \mathrm{m}^{2}$ ) and chronic kidney disease. Similarly, patients with peripheral artery disease are considered as a high-risk group for hemorrhagic events. Safety of bivalirudin was tested in the group of patients undergoing percutaneous peripheral interventions. The total number of hemorrhagic complications was lower, especially hematomas at the puncture site in comparison to patients receiving UFH [17]. Therefore, use of 
Table 1. Procedural and clinical factors in favor of the use of bivalirudin instead of unfractionated heparin during percutaneous coronary intervention in acute coronary syndrome.

Procedural and pharmacological factors
Femoral access
Chronic use of NOAC/VKA (uninterrupted)
Pre-treatment with oral potent $\mathrm{P} \mathrm{Y}_{12}$ inhibitor
(ticagrelor, prasugrel)
Patient-related factors
Age $>75$ years
Female gender
BMI $<20$ or BMI $>30 \mathrm{~kg} / \mathrm{m}^{2}$
Previous gastrointestinal bleeding
Previous hemorrhagic stroke
Chronic kidney disease (eGFR $30-60 \mathrm{ml} / \mathrm{min}_{1} 1.73 \mathrm{~m}^{2}$ )
Frailty
Increased bleeding risk related to other factors
Anticoagulant of choice
Heparin-induced thrombocytopenia

BMI - body mass index; eGFR - estimated glomerular filtration rate; NOAC - non-vitamin K antagonist oral anticoagulants; VKA - vitamin $\mathrm{K}$ antagonists

bivalirudin should be considered in all patients with increased risk of bleeding, who undergo PCI for ACS regardless of the type of vascular access and use of GPI (Table 1, Fig. 1). To reduce this risk of acute and long-term stent thrombosis a potent antiplatelet treatment with either ticagrelor or prasugrel could be considered in patients not requiring oral anticoagulation. As the potent $\mathrm{P} 2 \mathrm{Y}_{12}$ inhibitors were not available at the time when the summary of product characteristic (SPC) for bivalirudin was developed (20.09.2004), this combination was not included in the drug documentation.

\section{Bivalirudin and glycoprotein IIb/IIIa inhibitors}

In patients treated with bivalirudin the use of GPI (eptifibatide, abciximab, tirofiban) is safe and may be considered as bailout in selected clinical scenarios, i.e. thrombus visible in coronary angiography, acute stent thrombosis [18-20]. Although, in clinical practice the use of GPI in bivalirudintreated patients will be less common that in those on UFH.

\section{Periprocedural vs. prolonged infusion of bivalirudin}

Conflicting data exist as far as prolonged bivalirudin infusion is concerned in ACS [3, 21]. Most evidence for the bivalirudin use came from clinical trials in which patients were treated with less potent oral P2 $\mathrm{Y}_{12}$ inhibitors (clopidogrel). At that time prolonged infusion up to 4 hours after PCI seemed to be rational especially in STEMI and has been included in the SPC developed several years ago (20.09.2004). Acute stent thrombosis is a modifiable phenomenon and is reduced mainly by use of potent $\mathrm{P}_{2} \mathrm{Y}_{12}$ inhibitors (ticagrelor, prasugrel) [22, 23]. Therefore, in respect to the published data and clinical experience, in patients pre-treated with ticagrelor or prasugrel, in whom the PCI result is optimal, the periprocedural bivalirudin infusion should be continued after the procedure to empty the first vial of the drug only.

\section{Bivalirudin as an anticoagulant therapy in special situations}

A similar safety and efficacy profile of bivalirudin and UFH has also been demonstrated in cardiac surgery patients. The use of bivalirudin should be considered as an alternative for patients treated with extracorporeal membrane oxygenation (ECMO) or ventricular assist devices, requiring long-term treatment with heparin, which significantly increases the risk of heparin-induced thrombocytopenia [24].

\section{Cost-effectiveness of bivalirudin and reimbursement indications}

Historically bivalirudin vs. heparin has been shown as a cost-effective option in multiple countries [25, 26]. In Poland, despite higher per patient costs associated with the administration of bivalirudin (1,750 PLN) than UFH (100 PLN), the Agency for Health Technology Assessment and Tariff System (AOTMiT) confirmed that use of bivalirudin is cost-effective also in the Polish healthcare system. Bivalirudin is reimbursed by the National Health Fund and a higher initial cost is offset by the reduction in bleeding events, transfusion, urgent surgical procedures and length of hospital stay, which increase the cost of hospitalization by nearly $40 \%$.

As by the Polish reimbursement catalogue, bivalirudin is currently indicated in patients with MI (STEMI or NSTEMI) to optimize PCI outcomes. This reimbursement code $(5.53 .01 .0001469)$ is 


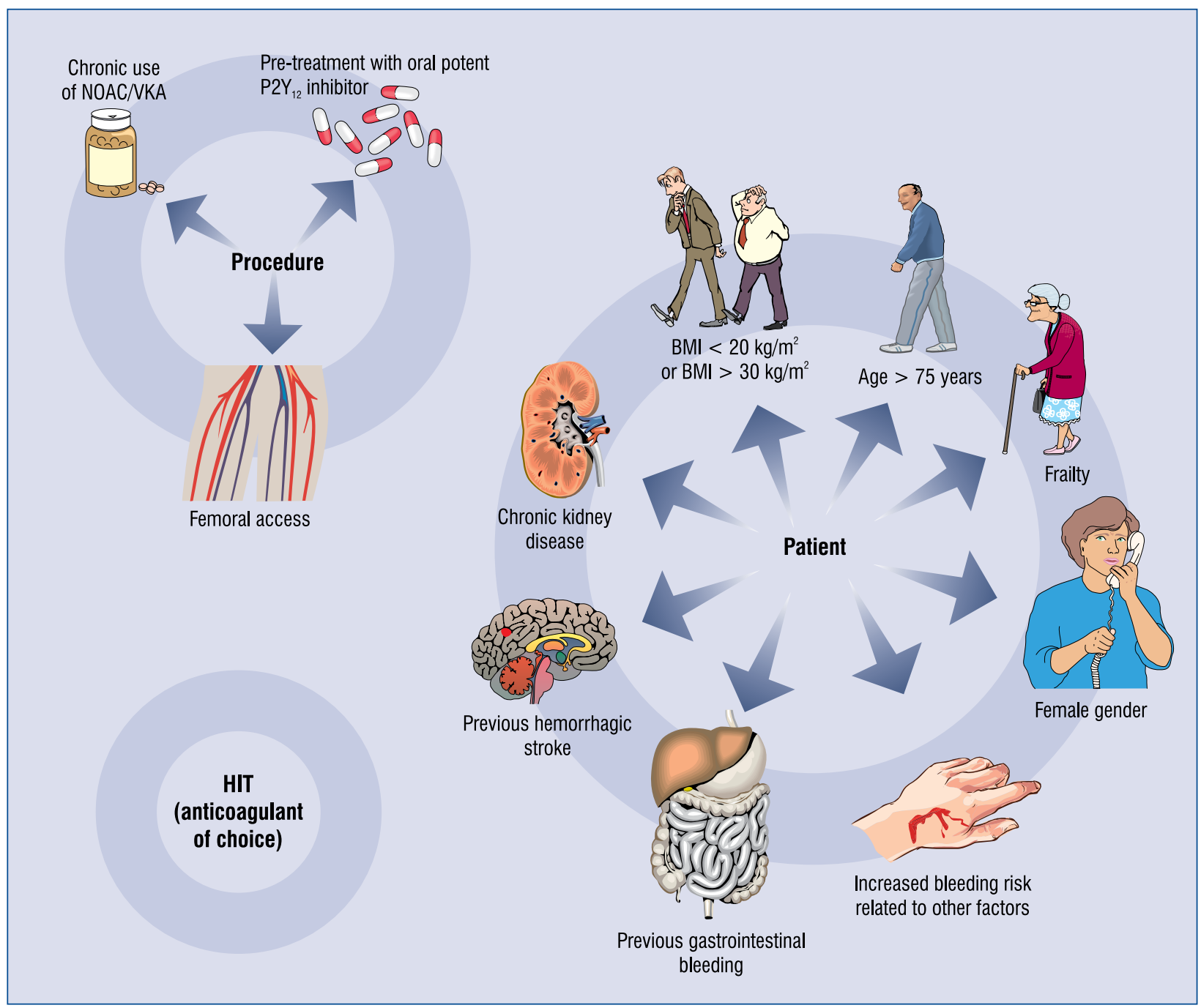

Figure 1. Procedural and clinical factors in favor of the use of bivalirudin instead of unfractionated heparin during percutaneous coronary intervention in acute coronary syndrome; BMI — body mass index; HIT — heparin-induced thrombocytopenia; NOAC — non-vitamin K antagonist oral anticoagulants; VKA — vitamin K antagonists.

unlimited and is not subtracted from the annual contract budget. This code can be claimed when added up to the primary $\mathrm{PCI}$ procedure, in specific the two-stage PCI for ACS > 3 days (E11), PCI for ACS (E12G) and PCI for ACS with complications $>7$ days (E15). We recommend that bivalirudin is used in all MI patients with high bleeding risk (as defined in Table 1 and Fig. 1). Thus, in the remaining patients, characterized by a low bleeding and high ischemic risk, a GPI should be considered. We urge that a detailed analysis is required to establish an incremental cost-effectiveness ratio from the healthcare service provider perspective in the real-world setting.

\section{Summary}

Recently published studies and the metaanalyses allow to better define the indications for bivalirudin in ACS patients undergoing PCI. Bivalirudin in contrast to UFH is characterized by more predictable anticoagulation effect and shorter half-life time. It has been showed that administration of bivalirudin in the periprocedural phase was associated with lower risk of all bleeding and major bleeding events that may translate to lower all-cause mortality and cardiovascular death. Therefore, the use of bivalirudin should be considered in all ACS patients with high bleeding 
risk, including patients on NOAC, female, elderly, obese and with chronic kidney disease. It is important to ensure regular review of new evidence to identify future subgroups of patients that may benefit most from bivalirudin as compared to standard UFH treatment.

\section{KEY MESSAGES}

The use of bivalirudin may be considered as an alternative to UFH in selected ACS patients to optimize $\mathrm{PCl}$ outcomes

Specific benefits can be expected in high bleeding risk patients, especially:

- Procedural and pharmacological factors: femoral access, chronic use of NOAC/vitamin K antagonists, pre-treatment with oral potent $\mathrm{P}_{2} \mathrm{Y}_{12}$ inhibitor

- Patient-related factors: age $>75$ years, female gender, $\mathrm{BMI}<20$ or $\mathrm{BMI}>30 \mathrm{~kg} / \mathrm{m}^{2}$, previous gastrointestinal bleeding, previous hemorrhagic stroke, chronic kidney disease (estimated glomerular filtration rate $30-60 \mathrm{~mL} / \mathrm{min} / 1.73 \mathrm{~m}^{2}$ ), frailty, increased bleeding risk related to other factors

- Anticoagulant of choice: heparin-induced thrombocytopenia

The recently updated reimbursement bivalirudin code allows for its unlimited use in MI patients undergoing $\mathrm{PCl}$ in Poland

Conflict of interest: Łukasz Kołtowski Accord, AstraZeneca, Boehringer Ingelheim, Polpharma; Jacek Legutko - AstraZeneca, Bayer, MSD; Krzysztof J. Filipiak - AstraZeneca, Bayer, Boehringer Ingelheim, MSD, Pfizer, Polpharma, Sanofi Aventis; Artur Dziewierz - none declared; Stanisław Bartuś - none declared; Paweł Buszman - none declared; Piotr Buszman - none declared; Dariusz Ciećwierz - none declared; Maciej Dąbrowski - none declared; Slawomir Dobrzycki - AstraZeneca, Bayer, Boehringer Ingelheim, MSD, Pfizer, Polpharma, Sanofi Aventis; Robert Gil - Bayer; Jarosław Gorący - none declared; Marek Grygier — none declared; Miłosz Jaguszewski - Boheringer Ingelheim, Abbott, Servier, AstraZeneca, Pfizer; Janusz Kochman none declared; Jacek Kubica - AstraZeneca, Bayer, Boehringer Ingelheim, Pfizer, Sanofi Aventis; Wiktor Kuliczkowki - AstraZeneca, Bayer, Boehringer Ingelheim, Boston Scientific; Piotr Lodziński - none declared; Andrzej Ochała none declared; Krzysztof Reczuch — none declared; Adam Witkowski - none declared; Wojciech Wojakowaki - none declared; Jarosław Wójcik none declared; Dariusz Dudek — Accord.

\section{References}

1. Sanchis-Gomar F, Perez-Quilis C, Leischik R, et al. Epidemiology of coronary heart disease and acute coronary syndrome. Ann Transl Med. 2016; 4(13): 256, doi: 10.21037/atm.2016.06.33, indexed in Pubmed: 27500157.

2. Wożakowska-Kapłon B, Lesiak M, Ochała A, et al. [Bivalirudine use in the acute myocardial infarction in patients undergoing percutaneous coronary interventions: consensus statement of experts from the Cardiovascular Pharmacotherapy Working Group and the Association on Cardiovascular Interventions of the Polish Cardiac Society]. Kardiol Pol. 2014; 72(8): 761-765, doi: 10.5603/ KP.2014.0159, indexed in Pubmed: 25155855.

3. Valgimigli M, Frigoli E, Leonardi S, et al. Radial versus femoral access and bivalirudin versus unfractionated heparin in invasively managed patients with acute coronary syndrome (MATRIX): final 1-year results of a multicentre, randomised controlled trial. Lancet. 2018; 392(10150): 835-848, doi: 10.1016/S01406736(18)31714-8, indexed in Pubmed: 30153988.

4. Shah R, Jovin IS, Chaudhry A, et al. Safety and efficacy of switching from unfractionated heparin to bivalirudin during primary percutaneous coronary intervention. Catheter Cardiovasc Interv. 2019; 93(2): 241-247, doi: 10.1002/ccd.27828, indexed in Pubmed: 30269393.

5. Anantha-Narayanan M, Anugula D, Gujjula NR, et al. Bivalirudin versus heparin in percutaneous coronary intervention: A systematic review and meta-analysis of randomized trials stratified by adjunctive glycoprotein IIb/IIIa strategy. J Thorac Dis. 2018; 10(6): 3341-3360, doi: 10.21037/jtd.2018.05.76, indexed in Pubmed: 30069330.

6. Grajek S, Michalak M, Gwizdała A, et al. Patients treated with bivalirudin are still at higher risk of stent thrombosis: a comprehensive meta-analysis of randomised clinical trials of bivalirudin and heparin for percutaneous coronary interventions. Kardiol Pol. 2018; 76(4): 740-749, doi: 10.5603/KP.a2018.0024, indexed in Pubmed: 29350380.

7. Neumann F-J, Ahlsson A, Alfonso F, et al. 2018 ESC/EACTS Guidelines on myocardial revascularization. Eur Heart J. 2018; 34(10): 2949.

8. Kereiakes D, Yeh R, Massaro J, et al. Stent thrombosis in drugeluting or bare-metal stents in patients receiving dual antiplatelet therapy. JACC: Cardiovasc Interv. 2015; 8(12): 1552-1562, doi: 10.1016/j.jcin.2015.05.026.

9. Kam PCA, Kaur N, Thong CL. Direct thrombin inhibitors: pharmacology and clinical relevance. Anaesthesia. 2005; 60(6): 565-574, doi: 10.1111/j.1365-2044.2005.04192.x, indexed in Pubmed: 15918828 .

10. Alquwaizani M, Buckley L, Adams C, et al. Anticoagulants: A Review of the Pharmacology, Dosing, and Complications. Curr Emerg Hosp Med Rep. 2013; 1(2): 83-97, doi: 10.1007/s40138013-0014-6, indexed in Pubmed: 23687625.

11. Cannon CP, Maraganore JM, Loscalzo J, et al. Anticoagulant effects of hirulog, a novel thrombin inhibitor, in patients with coronary artery disease. Am J Cardiol. 1993; 71(10): 778-782, indexed in Pubmed: 8456753.

12. Stratmann G, deSilva A, Tseng E, et al. Reversal of direct thrombin inhibition after cardiopulmonary bypass in a patient with heparin-induced thrombocytopenia. Anesth Analg. 2004: 1635-1639, doi: 10.1213/01.ane.0000114072.71353.d5. 
13. Valgimigli M, Frigoli E, Leonardi S, et al. Bivalirudin or Unfractionated Heparin in Acute Coronary Syndromes. N Engl J Med. 2015; 373(11): 997-1009, doi: 10.1056/nejmoa1507854.

14. Erlinge D, Omerovic E, Fröbert O, et al. Bivalirudin versus Heparin Monotherapy in Myocardial Infarction. N Engl J Med. 2017; 377(12): 1132-1142, doi: 10.1056/nejmoa1706443.

15. Witkowski A, Barylski M, Filipiak KJ, et al. Non-vitamin K antagonist oral anticoagulants (NOACs) in the treatment of coronary and peripheral atherosclerosis. Expert Consensus. Kardiol Pol. 2019 [Epub ahead of print], doi: 10.5603/KP.a2019.0033, indexed in Pubmed: 30799544.

16. Mallifi JR, Lotfi AS. Management of STEMI in Patients on NOACs and Undergoing Primary PCI. Expert Analysis ACC website 2015. https://www.acc.org/latest-in-cardiology/articles/2015/ /10/22/10/43/management-of-stemi-in-patients-on-noacs-andundergoing-primary-pci.

17. Wojtasik-Bakalarz J, Kleczyński P, Zasada W, et al. Safety of bivalirudin versus unfractionated heparin in endovascular revascularization of peripheral arteries in short- and long-term follow-up. Advances in Inverventional Cardiology. , doi: 10.5114/ /aic.2019.81757.

18. Stone GW, Maehara A, Witzenbichler B, et al. Intracoronary abciximab and aspiration thrombectomy in patients with large anterior myocardial infarction: the INFUSE-AMI randomized trial. JAMA. 2012; 307(17): 1817-1826, doi: 10.1001/jama.2012.421, indexed in Pubmed: 22447888.

19. Stone GW, Witzenbichler B, Guagliumi G, et al. Bivalirudin during primary $\mathrm{PCI}$ in acute myocardial infarction. N Engl J Med. 2008; 358(21): 2218-2230, doi: 10.1056/NEJMoa0708191, indexed in Pubmed: 18499566.
20. Stone G, McLaurin B, Cox D, et al. Bivalirudin for patients with acute coronary syndromes. N Engl J Med. 2006; 355(21): 2203-2216, doi: 10.1056/nejmoa062437.

21. Steg PG, van 't Hof A, Hamm CW, et al. Bivalirudin started during emergency transport for primary PCI. N Engl J Med. 2013; 369(23): 2207-2217, doi: 10.1056/NEJMoa1311096, indexed in Pubmed: 24171490.

22. Wallentin L, Becker RC, Budaj A, et al. Ticagrelor versus clopidogrel in patients with acute coronary syndromes. N Engl J Med. 2009; 361(11): 1045-1057.

23. Wiviott S, Braunwald E, McCabe C, et al. Prasugrel versus Clopidogrel in Patients with Acute Coronary Syndromes. N Engl J Med. 2007; 357(20): 2001-2015, doi: 10.1056/nejmoa07 06482.

24. Koster A, Faraoni D, Levy JH. Argatroban and bivalirudin for perioperative anticoagulation in cardiac surgery. Anesthesiology. 2018; 128(2): 390-400, doi: 10.1097/ALN.0000000000001976, indexed in Pubmed: 29206646.

25. Schwenkglenks M, Brazier JE, Szucs TD, et al. Cost-effectiveness of bivalirudin versus heparin plus glycoprotein IIb/IIIa inhibitor in the treatment of non-ST-segment elevation acute coronary syndromes. Value Health. 2011; 14(1): 24-33, doi: 10.1016/j. jval.2010.10.025, indexed in Pubmed: 21211483.

26. Borg S, Persson U, Allikmets K, et al. Comparative cost-effectiveness of anticoagulation with bivalirudin or heparin with and without a glycoprotein IIb/IIIa-receptor inhibitor in patients undergoing percutaneous coronary intervention in Sweden: a decision-analytic model. Clin Ther. 2006; 28(11): 1947-1959, doi: 10.1016/j.clinthera.2006.11.013, indexed in Pubmed: 17213015. 